\title{
High-bandwidth Modulation of H2/Syngas Fuel to Control Combustion Dynamics in Micro-Mixing Lean Premix Systems
}

\section{Final Technical Report}

\author{
Period of Performance \\ 10/1/2010 - 1/31/2012 \\ Principal Authors \\ Jeff Melzak \\ Dr. Tim Lieuwen \\ Dr. Adel Mansour (PI) \\ Report Issued \\ February 15, 2012 \\ DOE Award Number \\ DE-FE0005508 \\ Submitting Organization
}

Parker Hannifin Corporation - Gas Turbine Fuel Systems Division 8940 Tyler Blvd.

Mentor, OH 44060 USA

Phone: 440.266 .2300

Fax: 440.266 .2311

Taxpayer ID Number

34-045-1060

DUNS Number

123575784

$\underline{\text { CAGE Code }}$

2 Y939 
High-bandwidth Modulation of H2/Syngas Fuel to Control Combustion Dynamics in Micro-Mixing Lean Premix Systems

Final Technical Report

\section{DISCLAIMER}

This report was prepared as an account of work sponsored by an agency of the United States Government. Neither the United States Government nor any agency thereof, nor any of their employees, makes any warranty, express or implied, or assumes any legal liability or responsibility for the accuracy, completeness, or usefulness of any information, apparatus, product, or process disclosed, or represents that its use would not infringe privately owned rights. Reference herein to any specific commercial product, process, or service by trade name, trademark, manufacturer, or otherwise does not necessarily constitute or imply its endorsement, recommendation, or favoring by the United States Government or any agency thereof. The views and opinions of authors expressed herein do not necessarily state or reflect those of the United States Government or any agency thereof. 
High-bandwidth Modulation of H2/Syngas Fuel to Control Combustion Dynamics in Micro-Mixing Lean Premix Systems

Final Technical Report

\begin{abstract}
The goal of this program was to develop and demonstrate fuel injection technologies that will facilitate the development of cost-effective turbine engines for Integrated Gasification Combined Cycle (IGCC) power plants, while improving efficiency and reducing emissions. The program involved developing a next-generation multi-point injector with enhanced stability performance for lean premix turbine systems that burn hydrogen (H2) or synthesis gas (syngas) fuels. A previously developed injector that demonstrated superior emissions performance was improved to enhance static flame stability through zone staging and pilot sheltering. In addition, piezo valve technology was implemented to investigate the potential for enhanced dynamic stability through high-bandwidth modulation of the fuel supply. Prototype injector and valve hardware were tested in an atmospheric combustion facility.
\end{abstract}

The program was successful in meeting its objectives. Specifically, the following was accomplished:

- Demonstrated improvement of lean operability of the Parker multi-point injector through staging of fuel flow and primary zone sheltering;

- Developed a piezo valve capable of proportional and high-bandwidth modulation of gaseous fuel flow at frequencies as high as $500 \mathrm{~Hz}$;

- The valve was shown to be capable of effecting changes to flame dynamics, heat release, and acoustic signature of an atmospheric combustor.

The latter achievement indicates the viability of the Parker piezo valve technology for use in future adaptively controlled systems for the mitigation of combustion instabilities, particularly for attenuating combustion dynamics under ultra-lean conditions. 
High-bandwidth Modulation of H2/Syngas Fuel to Control

\section{TABLE OF CONTENTS}

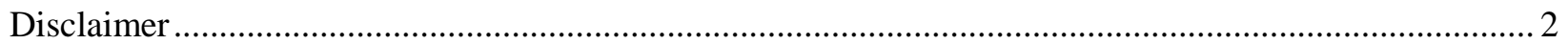

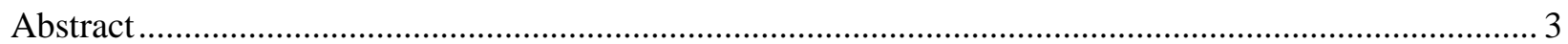

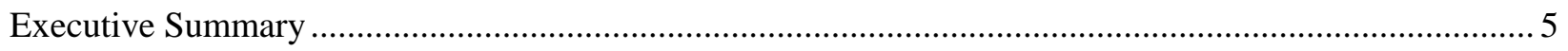

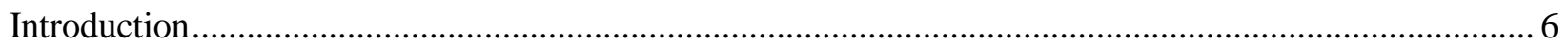

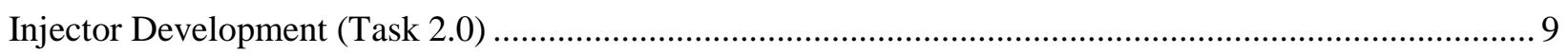

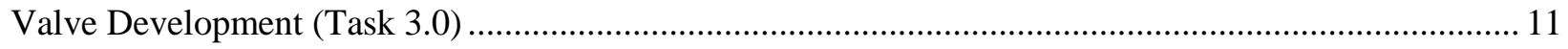

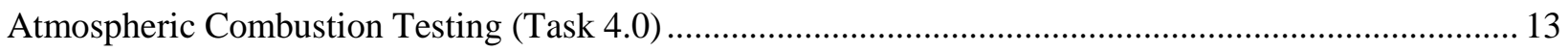

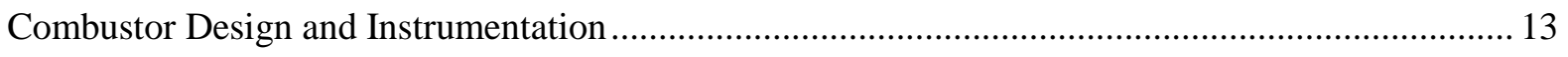

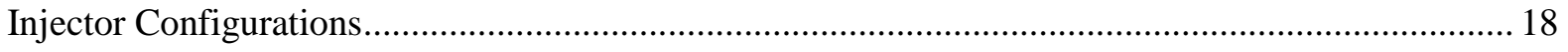

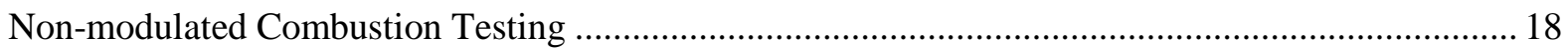

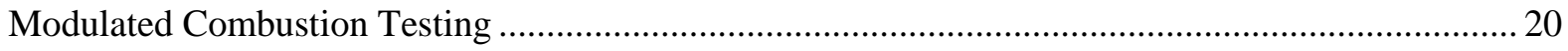

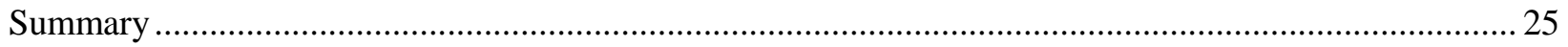

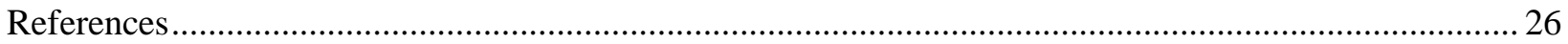




\section{High-bandwidth Modulation of H2/Syngas Fuel to Control Combustion Dynamics in Micro-Mixing Lean Premix Systems \\ Cooperative Agreement DE-FE0005508 \\ Final Technical Report}

\section{EXECUTIVE SUMMARY}

This is the final technical report for the above-titled program, for which the technical effort was completed by 12/31/2011. This report reviews program accomplishments and objectives, and presents results from the combustion experiments performed during the final quarter of the technical effort. Details of the injector development (Task 2.0), valve development (Task 3.0), and rig development (Task 4.1) have been presented in earlier quarterly progress reports, but will be reviewed herein for completeness. Lastly, an updated milestone chart will be presented.

The team was successful in accomplishing program objectives. Specifically, the following results were demonstrated experimentally:

- Improvement of lean operability through staging of fuel flow and primary zone sheltering;

- An operational piezo valve capable of proportional and high-bandwidth modulation of gaseous fuel flow at frequencies as high as $500 \mathrm{~Hz}$;

- The valve's ability to affect oscillation frequencies and amplitudes of combustor pressure and heat release.

The fuel injector and valve technology developed by Parker and demonstrated under this program show promise for next-generation low-NOx gas turbine engine systems. 
High-bandwidth Modulation of H2/Syngas Fuel to Control

Combustion Dynamics in Micro-Mixing Lean Premix Systems

Final Technical Report

\section{INTRODUCTION}

Suppression of combustion instabilities by feedback control has shown great potential over the last two decades. Multiple control schemes have been used successfully with a wide selection of sensors, actuators, and combustor geometries [1]. Experiments often show significant suppression of combustion instabilities accompanied by an overall lowering of the sound pressure level over the entire frequency spectrum [2]. In fact, an active control system has been successfully commercialized and fielded by Siemens for control of azimuthal instabilities in their V94.3A heavy duty gas turbines [3].

While significant progress has been made in demonstrating that active instability control is feasible, much work remains in two key areas: (1) understanding the factors influencing how effective control will be for a given system, and (2) development of practical, robust actuators capable of modulating fuel. Starting with the first item, the results of control implementation are highly variable. For example, even with their success, Siemens reported operating conditions where feedback control would excite combustion instabilities at other frequencies. In many applications, active control fails to fully suppress the original instability. The example of Siemens' experience [3] with active control limitations is not atypical; new combustion dynamics induced by feedback control is well-documented in compilations in the combustion instability literature [4]. A variety of factors can lead to compromised capabilities to suppress combustion instabilities. These include background noise floor levels, actuator control authority, actuator bandwidth, sensor location, and controlled combustor dynamics. Under the influence of feedback control, the limit cycle pressure response can exhibit a variety of behaviors associated with limited control effectiveness, such as peak splitting [5] and amplitude breathing [6].

Peak splitting manifests itself as a growth in oscillation amplitude at closely-spaced frequencies above and below the nominal instability frequency. The overall effect of peak splitting is to limit the maximum degree to which the oscillation amplitude can be suppressed. Significant breathing in instability amplitude is another typical observation in actively controlled combustors [7]. In this case, the average instability amplitude of the controlled combustor might be reduced significantly, but is associated 
High-bandwidth Modulation of H2/Syngas Fuel to Control Combustion Dynamics in Micro-Mixing Lean Premix Systems Final Technical Report

with significant variations in instability amplitude on a cycle-to-cycle basis. This is a serious issue given that one of these significant amplitude bursts could result in blowoff of the flame, among other problems.

In addition, fuel actuators pose a significant practical challenge associated with deployment of active control systems. The fuel actuator needs to have sufficient control authority and frequency response, as well as sufficient life. These considerations were a key motivation for this research effort.

This program is focused on the development of fuel injection technologies that will facilitate the development of cost-effective turbine engines for Integrated Gasification Combined Cycle (IGCC) power plants, while improving efficiency and reducing emissions. The program involves developing a nextgeneration multi-point injector with enhanced stability performance. The injector is shown in Figure 1 below. The primary module (the center 7 mixing cups) may be recessed relative to the secondary module (the outer 12 mixing cups), thereby sheltering the primary flow from the secondary flow to enhance static flame stability. Piezo valve technology was developed and implemented to investigate the potential for enhanced dynamic stability through high-bandwidth modulation of the primary fuel supply. The valve hardware is shown in Figure 2. Experimental tests were conducted in an atmospheric combustion facility at Georgia Tech using hydrogen fuel; the rig hardware is shown in Figure 3.
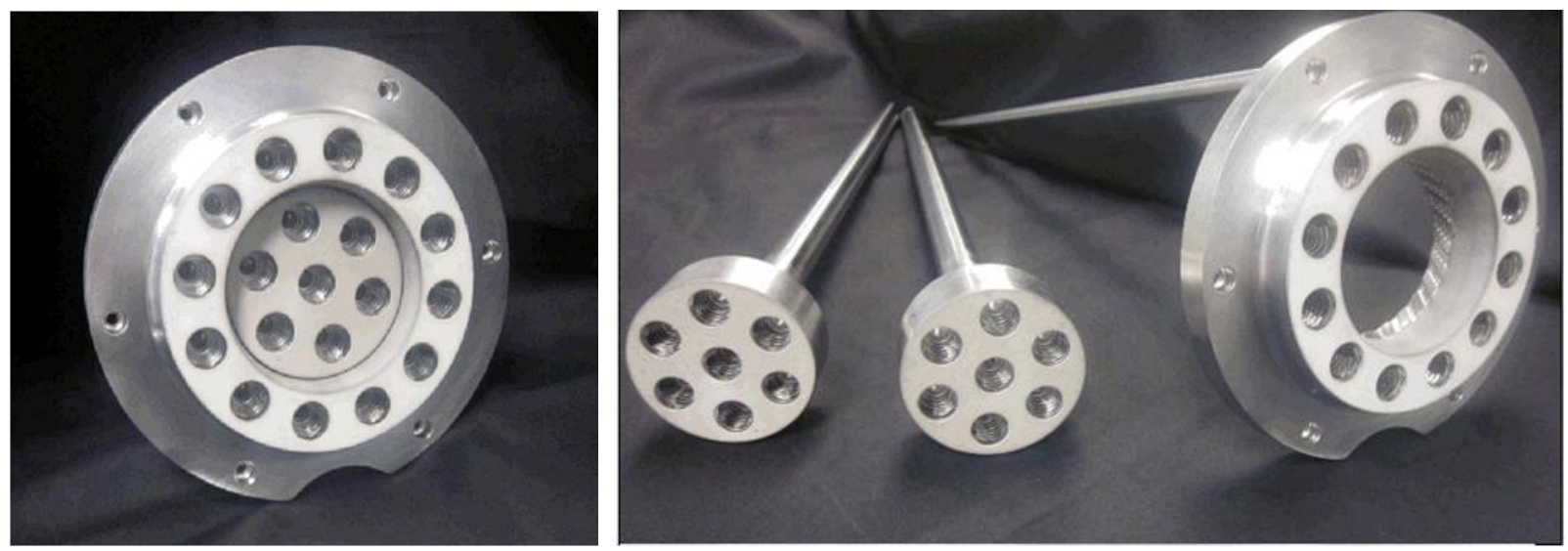

Figure 1: Multi-point injector hardware with separate primary and secondary. 
High-bandwidth Modulation of H2/Syngas Fuel to Control

Combustion Dynamics in Micro-Mixing Lean Premix Systems

Final Technical Report

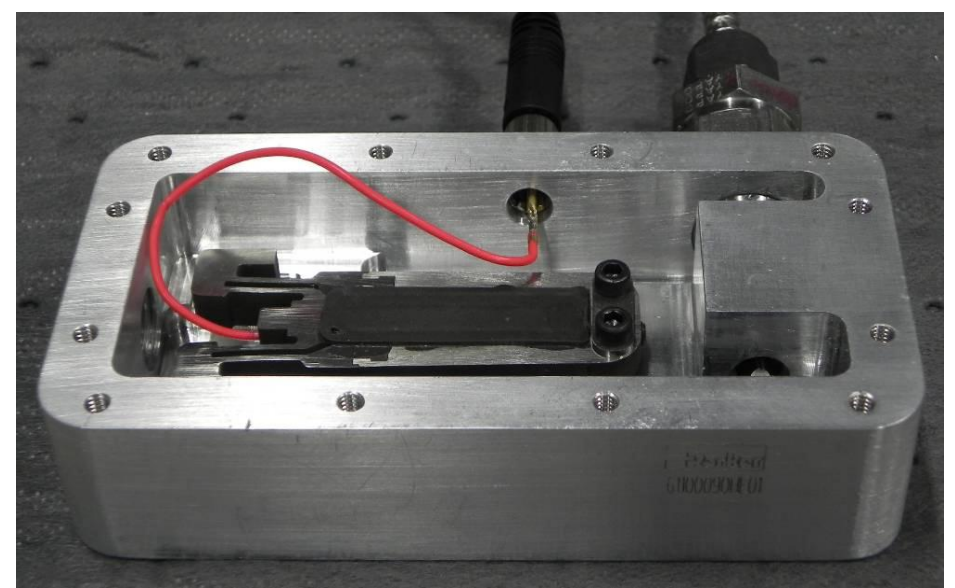

Figure 2: Piezo valve hardware (cover removed).
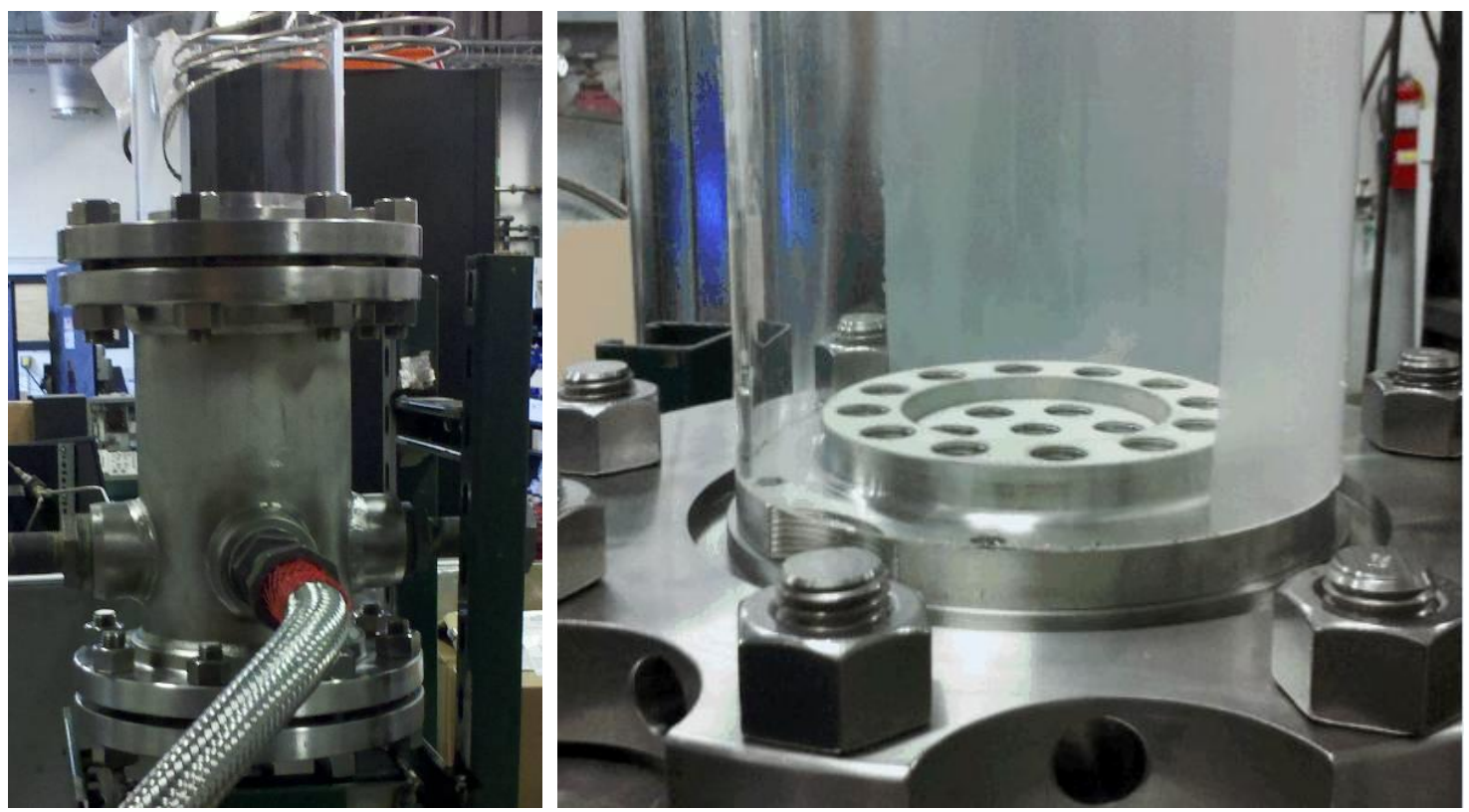

Figure 3: Atmospheric rig hardware with injector installed. 
High-bandwidth Modulation of H2/Syngas Fuel to Control

Combustion Dynamics in Micro-Mixing Lean Premix Systems

Final Technical Report

\section{INJECTOR DEVELOPMENT (TASK 2.0)}

One aspect of this program is to develop modular multi-point injectors to investigate the advantages and disadvantages of employing strategies for a sheltered primary zone for enhanced lean stability in a lean-premix combustion system. Control of mixing between the primary and secondary zones is of prime importance at lean conditions, particularly in a primary-only staged mode with only air flowing through the secondary.

The injector is based on a predecessor design that had been developed (in part) under an earlier DOE program and shown to produce ultra-low levels of NOx in a high-pressure combustion rig with hydrogen/syngas fuels. The current design (see Figure 1) contains 19 micro-mixing cups -7 in the primary fuel circuit and 12 in the secondary. The two fuel circuits are independently fed to allow for staging. In addition, the axial position of the primary injector is adjustable with respect to the secondary position, to allow for sheltering. Two versions of the primary injector were fabricated; they differ in the swirl direction of the micro-mixing cups. Due to resource constraints, however, only one version (counter-swirl) was tested.

The effective area of the fuel circuit (ACd) of each injector, as well as the series combination of the piezo valve and the primary injector, was measured as a function of pressure ratio (i.e., inlet pressure of fuel divided by outlet pressure) by Parker prior to shipping the injectors to Georgia Tech. Table 1 shows a summary of the effective area measurements at a pressure ratio of 1.2. Figure 4 shows a plot of discharge coefficient $(\mathrm{Cd})$ as a function of pressure ratio. Note that a restrictor was added to the primary fuel circuit to achieve approximately the same per-cup effective area in the primary and secondary injectors. 
Table 1: Injector and valve fuel circuit effective area measurements $(P R=1.2)$.

\begin{tabular}{|l|c|c|}
\hline & ACd (in ${ }^{2}$ ) @ 1.2 PR & ACd (in ${ }^{2}$ ) per cup \\
\hline Primary, delivered to GT (7 cups) & 0.01145 & 0.00164 \\
Primary, spare (7 cups) & 0.01146 & 0.00164 \\
Secondary (12 cups) & 0.01938 & 0.00162 \\
Piezo Valve (full open) & 0.01799 & - \\
Valve/Primary, spare (series, full open) & 0.01057 & 0.00151 \\
\hline
\end{tabular}

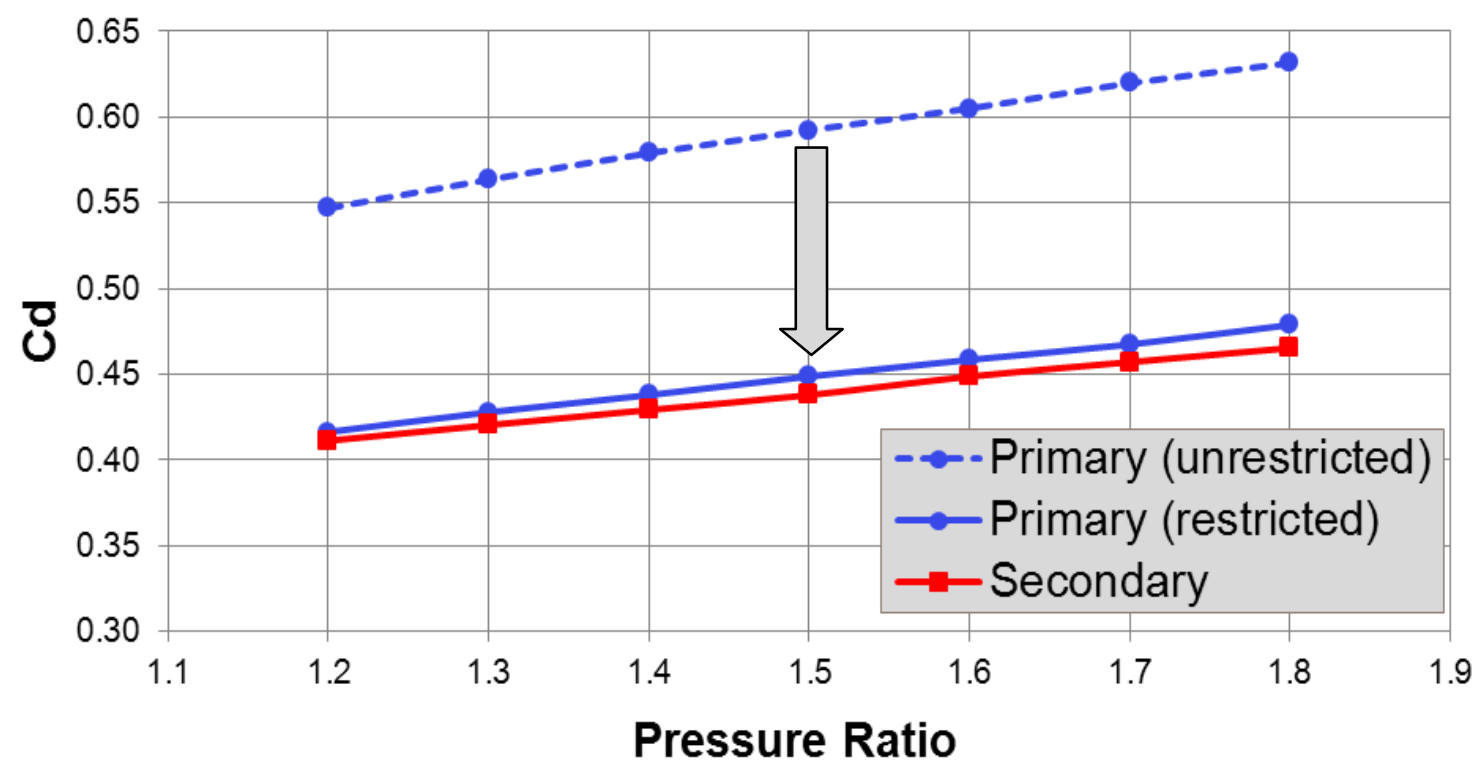

Figure 4: Measured injector fuel circuit discharge coefficient (Cd) vs. pressure ratio. 
High-bandwidth Modulation of H2/Syngas Fuel to Control

Combustion Dynamics in Micro-Mixing Lean Premix Systems

Final Technical Report

\section{VALVE DEVELOPMENT (TASK 3.0)}

The current program has two main objectives related to valve development. The first is to demonstrate a valve that is capable of both proportional and high-bandwidth modulation of gaseous fuel flow. The second is to demonstrate that the valve is able to effect changes to flame dynamics, heat release, and the acoustic signature of combustor. In order to meet these objectives, Parker undertook additional development of its piezo valve technology, as well as integration of the valve with the primary injector.

High-bandwidth fuel valves for control of combustion dynamics have proven to be a technology gap that is difficult to fill. The valve for this project is based on a novel piezo actuator that is proprietary to Parker. It contains a mechanical amplifier to provide force and stroke levels that are comparable to conventional electromechanical actuators, however with proportional response and much higher bandwidth capability. The standard actuator, which Parker has commercialized for industrial valve applications, was modified to operate in hydrogen fuel, and its bandwidth was increased to meet the $500 \mathrm{~Hz}$ requirement. The actuator is driven with an analog voltage from 0 to $170 \mathrm{~V}$, with a maximum stroke 0.054 ". The actuator in turn drives a pressure-balanced spool inside a stationary sleeve containing metering slots; as the actuator strokes, the flow area increases. The valve, when placed in series with the primary injector, is designed to modulate the effective area of the primary fuel circuit from $1 \%$ to $90 \%$ of the injector's nominal value (.0106 sq. in.), as shown in Figure 5.

The valve includes an in-situ displacement sensor to facilitate closed-loop operation based on spool position feedback. It was delivered to Georgia Tech with a LabView PID control routine that allows the operator to maintain target mean flow rate and modulation amplitude values for a given experimental setting, regardless of frequency. A screenshot of the controller is shown in Figure 6. 
High-bandwidth Modulation of H2/Syngas Fuel to Control

Combustion Dynamics in Micro-Mixing Lean Premix Systems

Final Technical Report

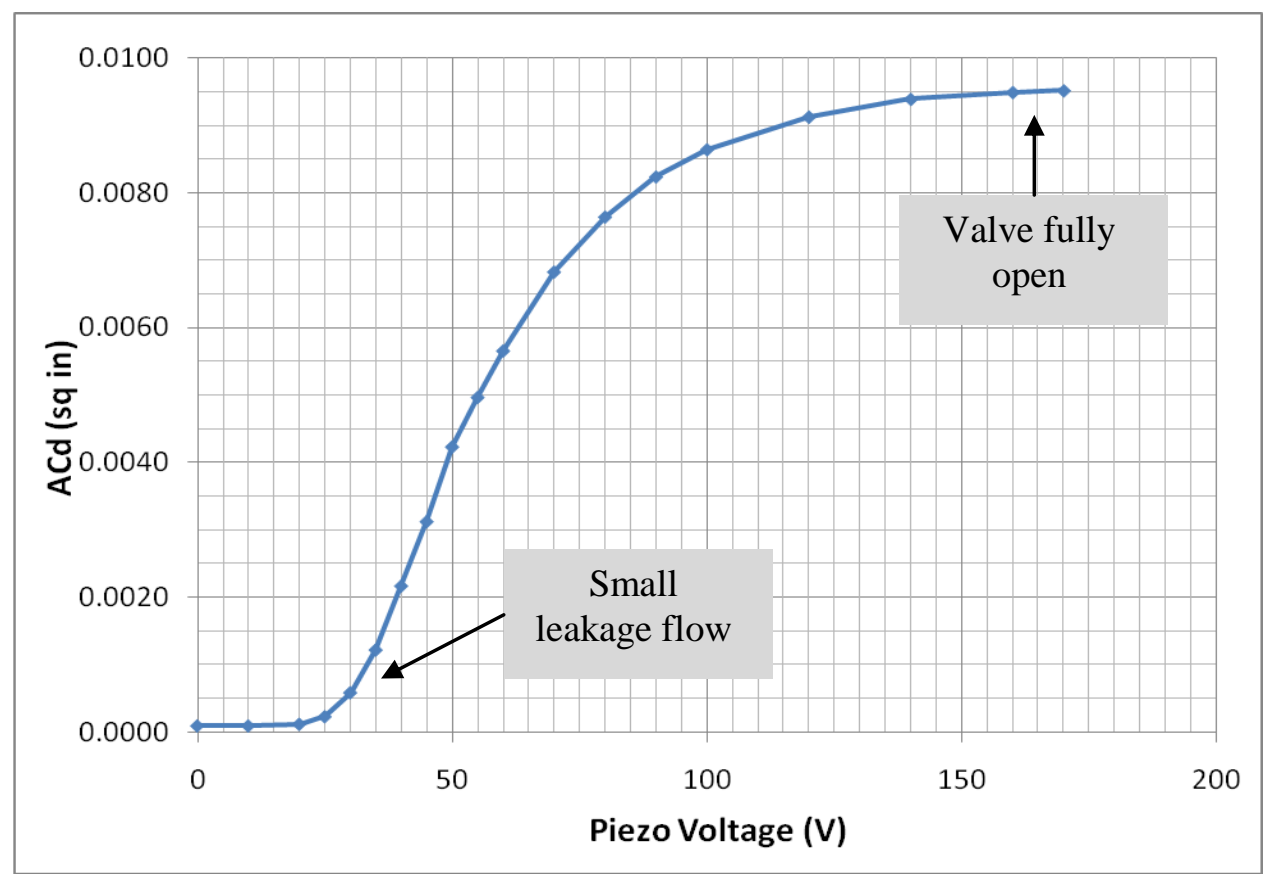

Figure 5: Measured fuel effective area of series combination of valve and primary injector as a function of piezo voltage.

\section{Dither Valve Controller 2011-10-10}

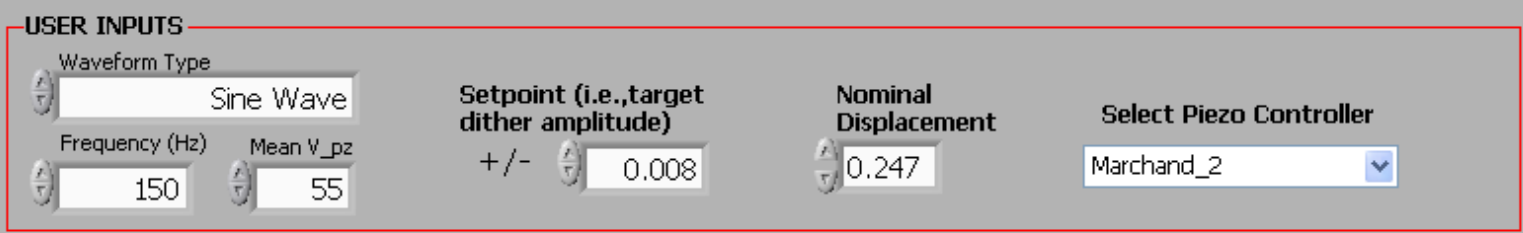

\begin{tabular}{|l|l|l|l}
\hline STOP & Measured displacement & Output within .001 of setpoint? & PID output \\
\hline
\end{tabular}

Piezo Voltage Waveform (V)

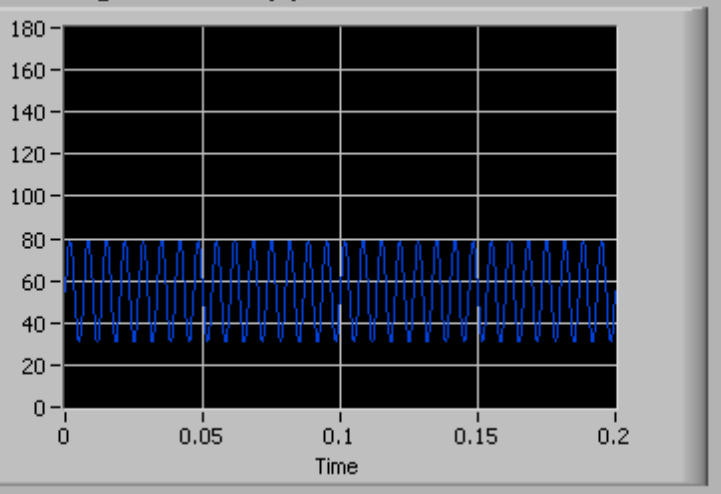

Measured Displacement (inches)

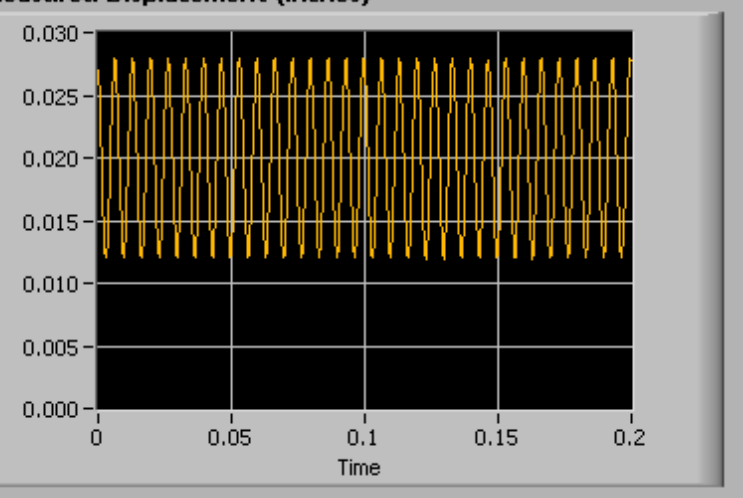

Figure 6: Screenshot of dynamic operation at $150 \mathrm{~Hz}$ with \pm .008 " displacement. 
High-bandwidth Modulation of H2/Syngas Fuel to Control

Combustion Dynamics in Micro-Mixing Lean Premix Systems

Final Technical Report

\section{ATMOSPHERIC COMBUSTION TESTING (TASK 4.0)}

Parker collaborated with subcontract partner Georgia Institute of Technology on this program. Detailed experimental studies were conducted at the Georgia Tech combustion lab during the last quarter to investigate the effects of various injector configurations and valve settings on combustion performance.

This section of the report will be organized as follows. First, the combustor design and instrumentation setup will be reviewed. Second, the injector configurations that were tested will be described. Third, the combustion experiments will be presented and the test matrix, results, and conclusions will be summarized. The combustion tests were divided into two main groups - nonmodulated (without the valve inline) and modulated. As was stated above, the experimental results in this section show that all of the program objectives were met.

\section{Combustor Design and Instrumentation}

This section describes the experimental setup used at the Georgia Institute of Technology Combustion Laboratory, including combustor sizing considerations, air and fuel delivery systems, rig instrumentation, and the data acquisition system.

\section{Combustor sizing considerations}

The primary objective of this test campaign is to characterize the response of the combustor to forced oscillations in the fuel feed at frequencies as high as $500 \mathrm{~Hz}$. With this in mind, the combustion chamber was sized to minimize any background acoustic modes that would occur in this range. The overall length was chosen to avoid a longitudinal mode, while minimizing any entrainment effect the surrounding air may have. An off-the-shelf 6" long quartz tube was found to satisfy the above conditions, and was selected for these tests. Figure 7 shows a photograph of the quartz tube installed in the rig. A tube outer diameter of $166 \mathrm{~mm}$ was selected based on injector face requirements. The combustor face was slightly larger than the injector outer diameter due to the placement of a dynamic pressure tap. The additional face area also provided a surface to mount the injector in place. 


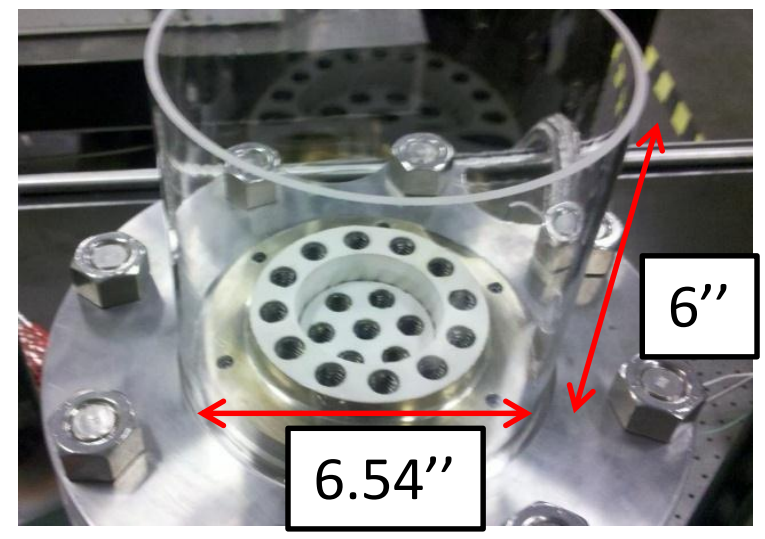

Figure 7: Photograph of rig with quartz tube and injector installed.

\section{Air Delivery System}

Air was supplied to the rig from a 125 psig building supply, providing continuous flow at approximately 0.2 to $0.3 \mathrm{lb} / \mathrm{sec}$. Figure 8 shows a piping and instrumentation diagram for the air system, and Table 2 provides a list of the relevant instrumentation. The flow rate was monitored using a subcritical orifice plate (FM-101), upstream static pressure (PT-101), and a high-accuracy differential pressure transducer (DPT-101). The air flow rate was adjusted by throttling a ball valve (MV-102) located downstream of the pressure and flow sensors. Air entered the rig through 4 flexible pipes which pressurized the airbox to deliver air to the injector at the desired pressure.

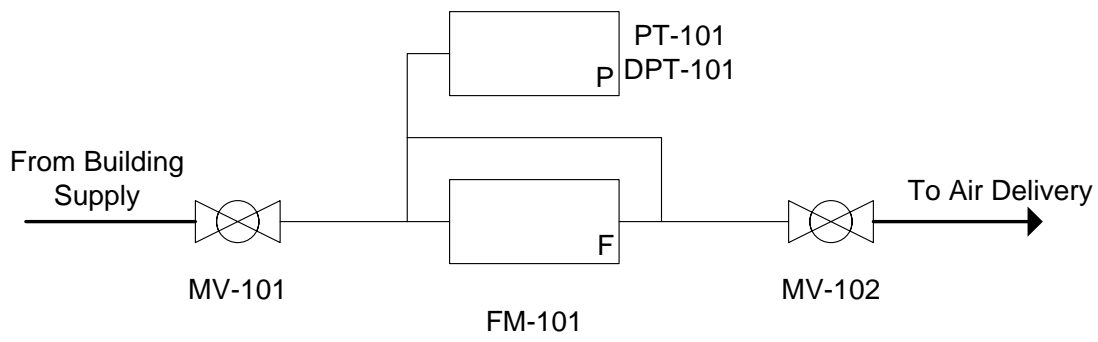

Figure 8: Schematic of air delivery system piping and instrumentation. 
High-bandwidth Modulation of H2/Syngas Fuel to Control Combustion Dynamics in Micro-Mixing Lean Premix Systems

Table 2: List of process piping and control instrumentation.

\begin{tabular}{|l|l|c|}
\hline \multicolumn{1}{|c|}{ Device } & \multicolumn{1}{|c|}{ Description } & Part Number \\
\hline MV-101 & Manual Ball Valve & - \\
MV-102 & Manual Ball Valve & - \\
FM-101 & Orifice Plate Flow Meter & - \\
PT-101 & Pressure Transducer & Omega PX209-300GI \\
DPT-101 & Differential Pressure Transducer & Omega PX76-250WCDI \\
PRV-201 & Pressure Regulator & Airgas Y12-N145G \\
CHV-201 & Check Valve & - \\
CV-201 & Solenoid Control Valve (NC) & ASCO Valve 8223G023 \\
CV-202 & Solenoid Control Valve (NO) & ASCO Valve 8210G033 \\
FM-201 & Orifice Plate Flow Meter & - \\
PT-201 & Pressure Transducer & Omega PX305-50GI \\
DPT-201 & Differential Pressure Transducer & Omega PX771A-100WCDI \\
MV-201 & Manual Ball Valve & - \\
MV-202 & Manual Ball Valve & - \\
MV-203 & Manual Ball Valve & - \\
MV-204 & Manual Ball Valve & - \\
PT-202 & Pressure Transducer & Omega PX305-50GI \\
DPT-202 & Differential Pressure Transducer & Omega PX771A-100WCDI \\
FM-202 & Orifice Plate Flow Meter & - \\
CV-203 & Piezo Actuated Control Valve & - \\
MV-205 & Manual Needle Control Valve & - \\
\hline
\end{tabular}

\section{Fuel Delivery System}

Figure 9 shows a piping and instrumentation diagram for the fuel system, and Table 2 shows a list of relevant instrumentation. Fuel was supplied via a 12-bottle rack of industrial grade hydrogen. The hydrogen pressure was first reduced to approximately 100-200 psig via a pressure reducing regulator (PRV-201), then traveled approximately 50 feet to the experiment. A set of block and bleed solenoids (CV-201, CV-202) insured the lines were properly purged until fuel flow was desired. The total hydrogen flow rate was measured using an orifice plate (FM-201), static pressure sensor (PT-201), and dynamic pressure sensor (DPT-201) similar to the setup described for the air system. The fuel traveled through a series of safety shut-off valves (MV-201, MV-202) before being split into primary and secondary delivery lines. The primary fuel flow rate was measured using an additional orifice plate meter (FM-202), while the secondary flow rate was derived by subtracting the primary flow rate from the total flow rate. The 
High-bandwidth Modulation of H2/Syngas Fuel to Control Combustion Dynamics in Micro-Mixing Lean Premix Systems

Final Technical Report

primary flow rate was controlled through one of two means. During static testing, the flow rate was controlled via a manual control valve (MV-203); during dynamic testing it was controlled with the Parker piezo actuated valve (CV-203). The piezo valve was positioned approximately 1 foot upstream from the entrance to the airbox. The secondary delivery was always controlled using a manual needle control valve (MV-205).

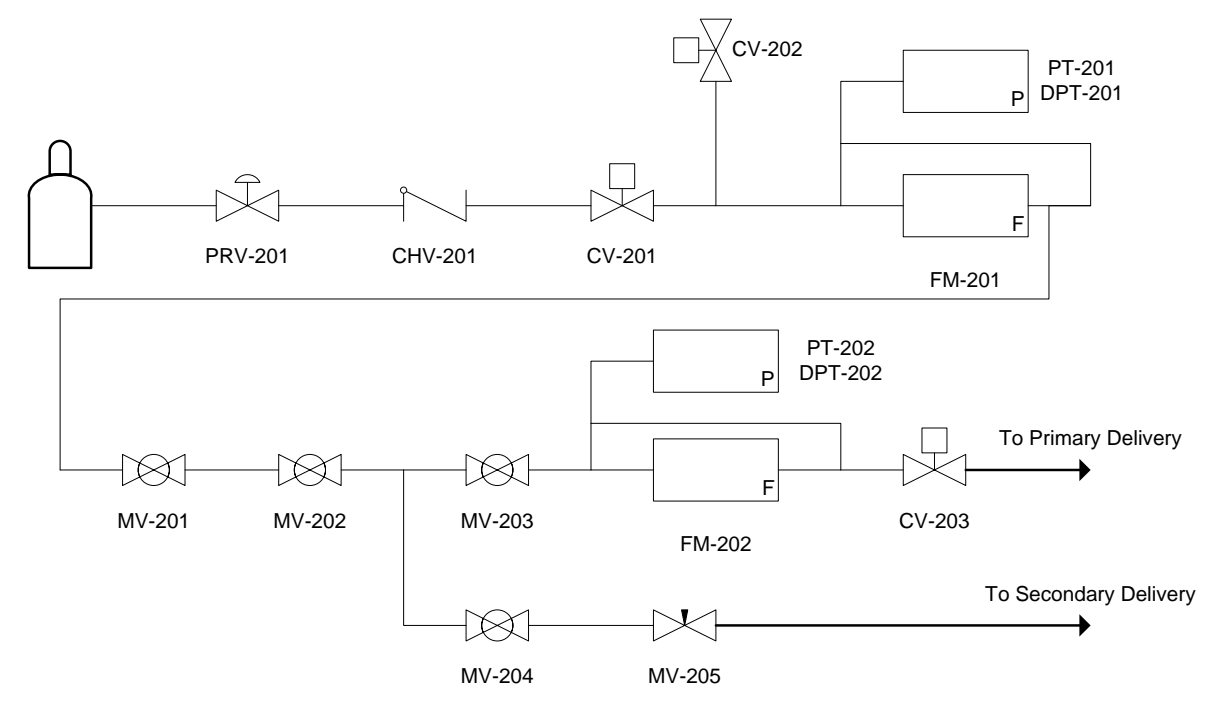

Figure 9: Schematic of fuel delivery system piping and instrumentation.

\section{$\underline{\text { Rig Instrumentation }}$}

The experiment was instrumented with three pressure transducers and one photomultiplier tube. An Omega PX209-50GI pressure transducer was utilized to measure airbox static pressure. This measurement was used to calculate the pressure drop across the injector (atmospheric pressure on the combustor side), which in turn was used to set the airflow rate. Kistler 601A dynamic pressure transducers were deployed into two of three available locations. The dynamic pressure could be measured in the primary fuel line (immediately downstream of the actuated valve), in the airbox, or at the combustor face. During static testing, the transducers were located in the airbox and combustor face, while during actuated testing they were located in the fuel line and combustor face. A Hamamatsu 
High-bandwidth Modulation of H2/Syngas Fuel to Control Combustion Dynamics in Micro-Mixing Lean Premix Systems Final Technical Report

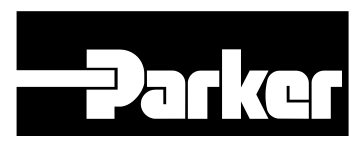

photomultiplier tube fit with a $310 \mathrm{~nm}$ band pass optical filter provided a measure of the time-resolved heat release of the combustor. Figure 10 shows the location of the instruments discussed above.

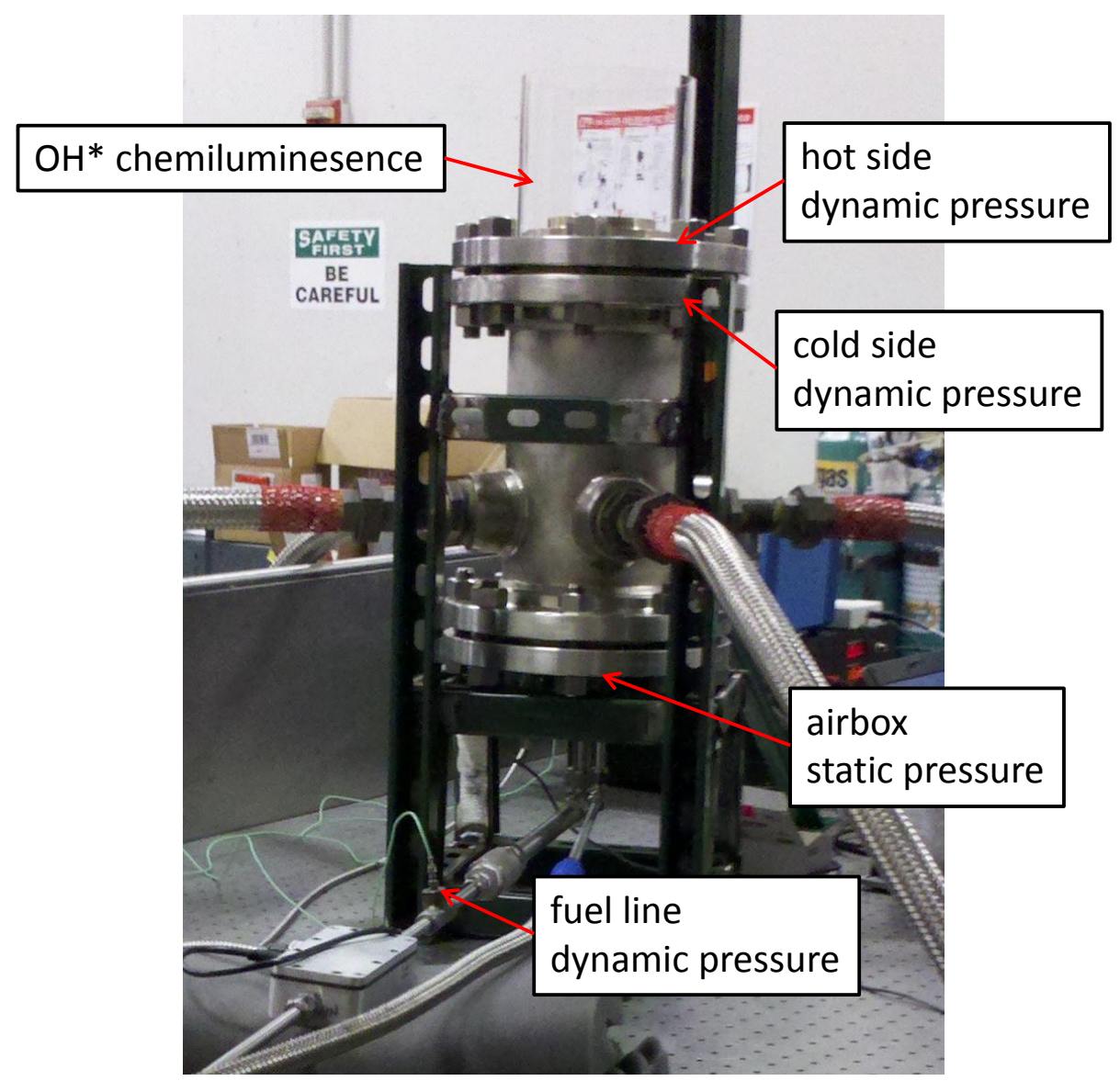

Figure 10: Locations of rig measurements.

\section{Data Acquisition}

All of the above instruments were read into a National Instruments CompactRIO data acquisition and control module. Software averaging was performed on all but the high speed measurements (i.e., dynamic pressure and photomultiplier measurements), for which a hardware filter was used. The data were reduced in real time and displayed via a LabView virtual interface. Low-speed data were recorded continuously, and written to a CSV-formatted text file once per second; high-speed measurements were recorded on demand at $25 \mathrm{kHz}$. Data were post-processed using MATLAB. 
High-bandwidth Modulation of H2/Syngas Fuel to Control Combustion Dynamics in Micro-Mixing Lean Premix Systems

Final Technical Report

\section{Injector Configurations}

As described earlier, the position of the primary fuel injector is adjustable in both the axial and rotational directions. To maintain a reasonably sized experimental matrix, 2 axial positions and 2 rotational positions were chosen for operability mapping, resulting in a total of 4 different configurations. Figure 11 shows a representation of these configurations. The axial position of the primary injector was either flush with the face of the secondary injector or recessed (i.e., sheltered) by 0.5 ". The rotational position was either "inline" or "offset"; for the inline configuration, a given primary cup and the closest secondary cup were aligned at the same clock angle, minimizing the distance between them. For the offset configuration, one primary cup was shared between its two nearest secondary cups.

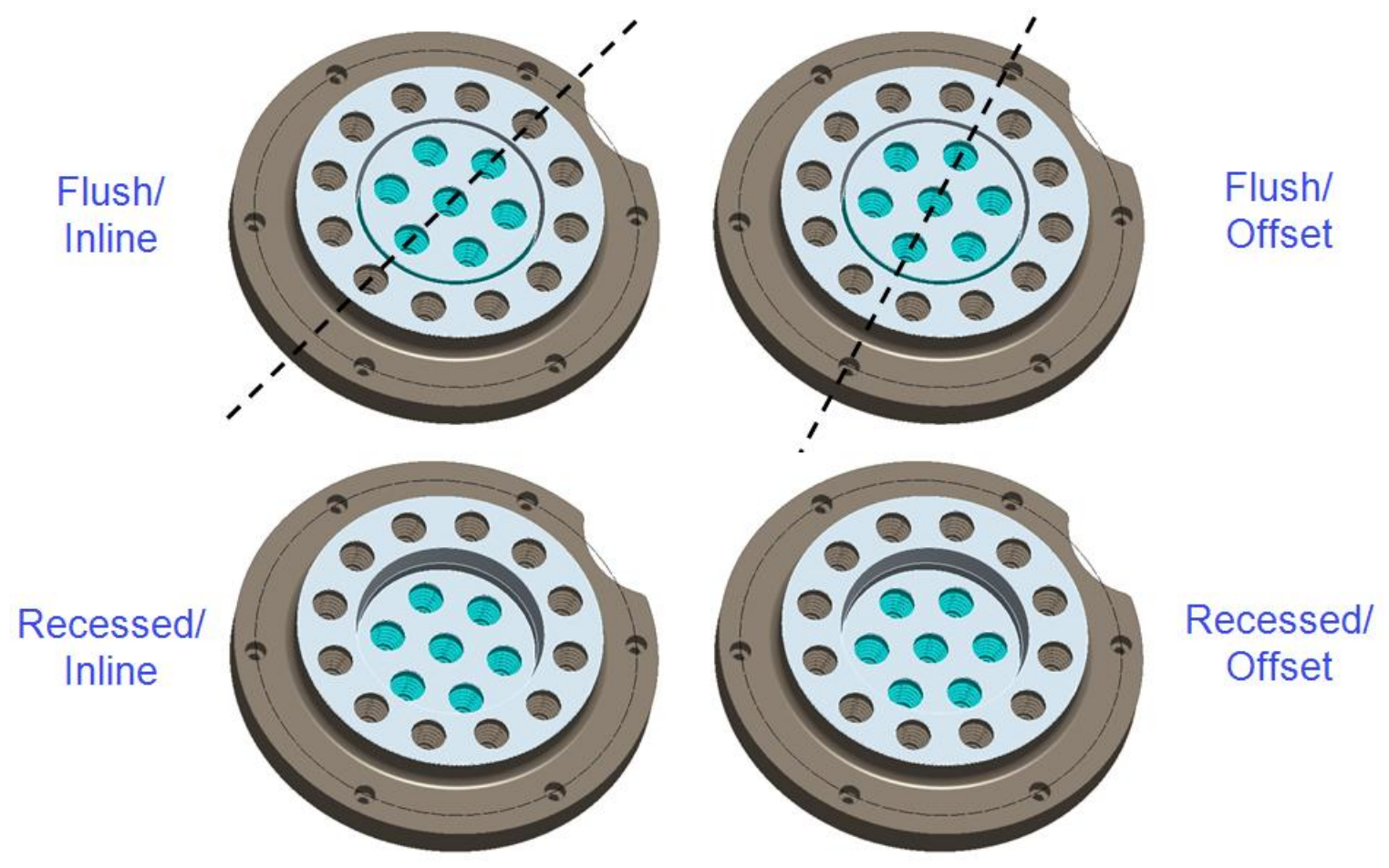

Figure 11: Injector configurations tested for operability mapping.

\section{Non-modulated Combustion Testing}

The combustion experiments were performed in two different sets. The first set was run with the injector operating under steady-state flow conditions (i.e., the valve was not installed). For each configuration described above, the operability range was investigated. Global equivalence ratio was 
High-bandwidth Modulation of H2/Syngas Fuel to Control Combustion Dynamics in Micro-Mixing Lean Premix Systems

Final Technical Report

recorded at ignition and lean blowout conditions. In addition, fuel staging was investigated - the injector was operated in three different ways: (i) primary circuit only fueled, (ii) secondary only fueled, and (iii) both primary and secondary fueled. Thus, the effects of both fuel staging and injector configuration on ignition and lean blowout were studied.

Figure 12 shows representative FFT's of combustor pressure for global equivalence ratios above (left) and below (right) 0.3. Note the appearance in both spectra of a broadband peak from $\sim 3500$ to 6000 $\mathrm{Hz}$, which was attributed to aerodynamic noise from the air supply. The difference between the two spectra is the presence of tonal peaks at 2700 and $5400 \mathrm{~Hz}$ for equivalence ratios above 0.3. These peaks correspond to the primary circumferential mode and its first harmonic. To avoid these peaks, global equivalence ratio was held below 0.3 for all experiments. In addition, note that within the valve's operating bandwidth (0 to $500 \mathrm{~Hz}$ ), the combustor pressure is "quiet" as intended.
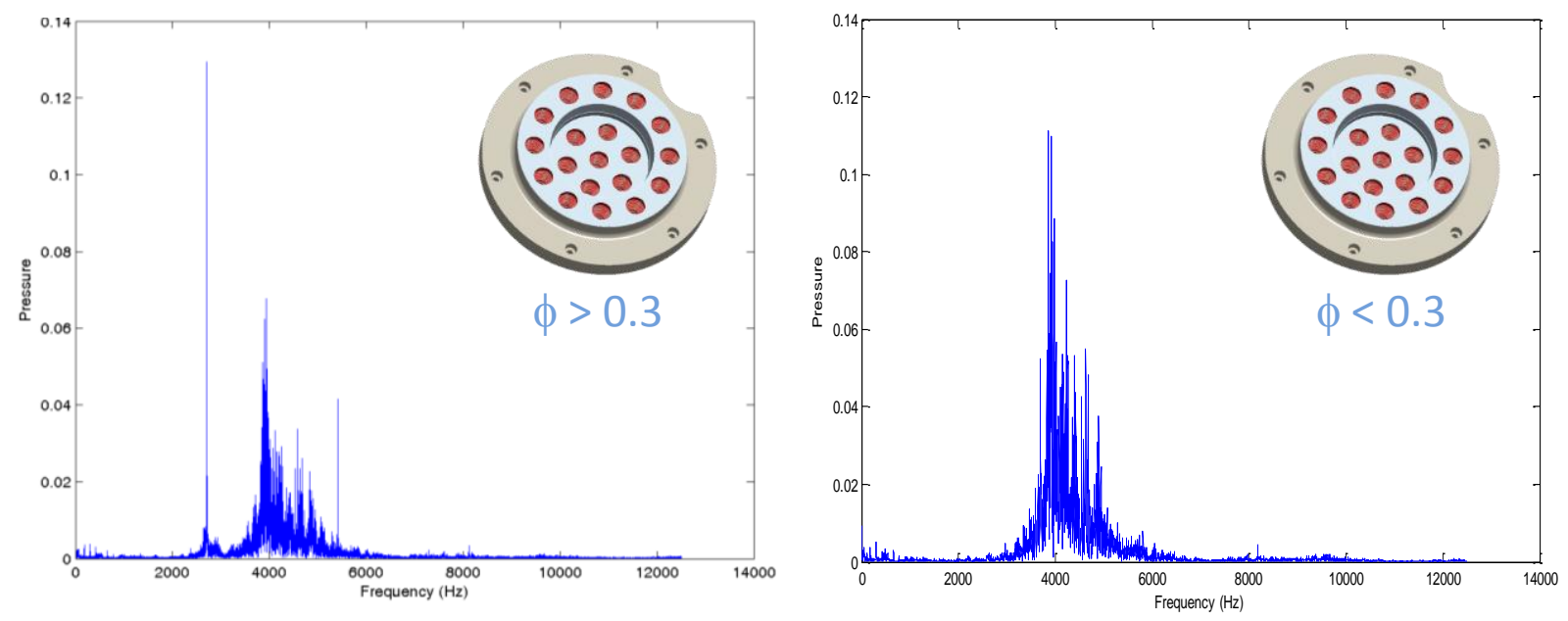

Figure 12: Combustor pressure FFT spectra.

Table 3 shows the global equivalence ratios measured at ignition and blowout for each injector configuration in the primary-only cases. (Note that only global equivalence ratios are reported, so comparison of absolute values should not be made across experiments that were fueled differently.) It was observed that the recessed configurations are favored for improved lean blowout by about $7 \%$. This demonstrates improvement of lean operability through staging of fuel flow and primary zone sheltering. For this configuration combustion occurs predominantly in the recessed zone; sheltering the pilot reduces 
High-bandwidth Modulation of H2/Syngas Fuel to Control Combustion Dynamics in Micro-Mixing Lean Premix Systems

the interaction between primary flame and the non-fueled secondary air, thereby resulting in minimum dilution of the primary flame.

Table 3: Ignition and blowout data with primary-only fueled.

\begin{tabular}{|c|c|c|c|c|}
\hline \multicolumn{2}{|c|}{ IGNITION } & & \multicolumn{2}{c|}{ BLOWOUT } \\
\hline Inline & Offset & & Inline & Offset \\
\hline .115 & .150 & Flush & .099 & .099 \\
\hline .112 & .115 & Recessed 0.5” & .092 & .092 \\
\hline
\end{tabular}

Table 4 shows the global equivalence ratios measured at ignition and blowout for each injector configuration in the secondary-only cases. Here the flush configurations are favored for blowout, showing an 18-25\% improvement over the recessed cases. For this configuration recessing the nonfueled pilot results in increased entrainment of the pilot air into the secondary combustion zone, thereby degrading lean operability.

Table 4: Ignition and blowout data with secondary-only fueled.

\begin{tabular}{|c|c|c|c|c|}
\hline \multicolumn{2}{|c|}{ IGNITION } & & \multicolumn{2}{c|}{ BLOWOUT } \\
\hline Inline & Offset & & Inline & Offset \\
\hline .145 & .150 & Flush & .116 & .130 \\
\hline .173 & .163 & Recessed 0.5” & .155 & .159 \\
\hline
\end{tabular}

Table 5 shows the global equivalence ratios measured at ignition and blowout for each injector configuration with both circuits fueled. Lean blowout is independent of configuration. It is believed the effects of the primary-only and secondary-only cases, described above, counteract each other when the fuel is not staged.

Table 5: Ignition and blowout data with primary and secondary fueled.

\begin{tabular}{|c|c|c|c|c|}
\hline \multicolumn{2}{|c|}{ IGNITION } & & \multicolumn{2}{c|}{ BLOWOUT } \\
\hline Inline & Offset & & Inline & Offset \\
\hline .227 & .168 & Flush & .162 & .162 \\
\hline .166 & .176 & Recessed 0.5” & .159 & .162 \\
\hline
\end{tabular}

\section{Modulated Combustion Testing}

Following completion of the non-modulated combustion tests, the piezo valve was installed in the primary fuel supply upstream of the injector. Subsequent combustion tests were performed with the valve in operation (sinusoidal drive) to study the effects of fuel modulation on heat release and combustor 
High-bandwidth Modulation of H2/Syngas Fuel to Control

Combustion Dynamics in Micro-Mixing Lean Premix Systems

Final Technical Report

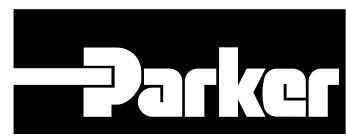

pressure oscillations. The injector configuration that demonstrated the best lean operability during the non-modulated tests - recessed/inline with primary fuel only - was chosen for all of the modulated combustion tests.

Prior to dynamic operation in the rig, the piezo valve's proportional metering capability was confirmed. To do this, the valve actuator was initially set to $60 \mathrm{~V}$, so that its effective area was approximately in the middle of the authority range. The combustor was ignited and the global equivalence ratio was then adjusted to a value of 0.18 . While holding the fuel delivery pressure and air flow rate constant, the valve's drive voltage was adjusted to different DC values and the resulting change in equivalence ratio was noted. Consistent with earlier (non-fired) bench tests, the valve flow area and global equivalence ratio both scaled with drive voltage. Furthermore, the spool displacement as a function of voltage was found to be repeatable and consistent with earlier bench test results.

The high-frequency modulation tests were performed following confirmation of valve/actuator performance under steady-state conditions. These tests had two primary objectives: (i) to demonstrate a valve technology capable of proportional and high-bandwidth modulation of gaseous fuel flow at frequencies as high as $500 \mathrm{~Hz}$, and (ii) to determine the valve's ability to impact changes in flame dynamics, heat release, and the acoustic signature of the combustor. Both of these objectives were accomplished by exploring a variety of modulation frequencies and amplitudes. The valve was operated with a sinusoidal waveform at frequencies ranging from 50 to $500 \mathrm{~Hz}$ and amplitudes ranging from \pm 0.002 " to \pm 0.018 ", although it should be noted that the maximum achievable amplitude decreased for frequencies above $\sim 225 \mathrm{~Hz}$. Combustor pressure, combustor heat release, and modulated fuel pressure were recorded at each operating condition. The raw data were post-processed with MATLAB to take Fast Fourier Transforms in order to study system response in the frequency domain.

Figure 13 shows a series of fuel line pressure spectra for a $200 \mathrm{~Hz}$ valve excitation at various amplitudes. The magnitude of the $200 \mathrm{~Hz}$ peak increases monotonically with amplitude, demonstrating the valve's ability to induce oscillations in fuel flow at the driving frequency that are proportional to the valve dither amplitude. This capability was demonstrated for frequencies as high as $500 \mathrm{~Hz}$, thereby 
High-bandwidth Modulation of H2/Syngas Fuel to Control Combustion Dynamics in Micro-Mixing Lean Premix Systems

meeting the first objective listed above; while a $500 \mathrm{~Hz}$ spectra is not presented here, combustor data shown below confirm the valve's ability to successfully modulate flow at this frequency.

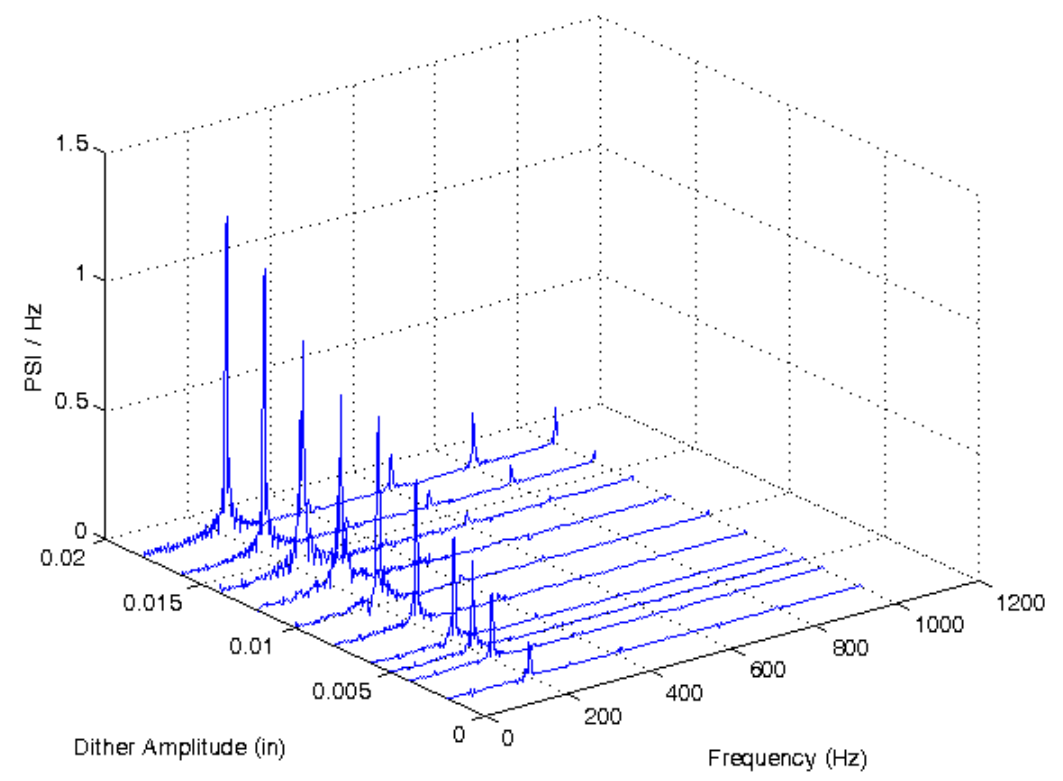

Figure 13: Fuel line pressure spectra for varying amplitudes at $200 \mathrm{~Hz}$.

Figure 14 shows the corresponding series of combustor pressure spectra (measured simultaneously with those shown in Figure 13). The combustor pressure spectra also show strong peaks at the driving frequency of $200 \mathrm{~Hz}$, along with smaller harmonic peaks, although the harmonics are damped. Furthermore, the same trend in peak height with increasing valve amplitude is observed. These results indicate that the valve is able to directly affect the frequency content of combustor pressure, i.e., that pressure oscillations induced by the valve are "transmitted" to the combustor. Figure 15 shows three spectra for a $300 \mathrm{~Hz}$ excitation with an amplitude of \pm 0.005 ”: fuel line pressure, combustor pressure, and heat release (from left to right). The same trend in combustor pressure is observed at this frequency. In addition, the heat release spectrum is nearly identical to the combustor pressure spectrum, indicating that heat release is also impacted in a deterministic way by modulating the fuel flow with the piezo valve. 


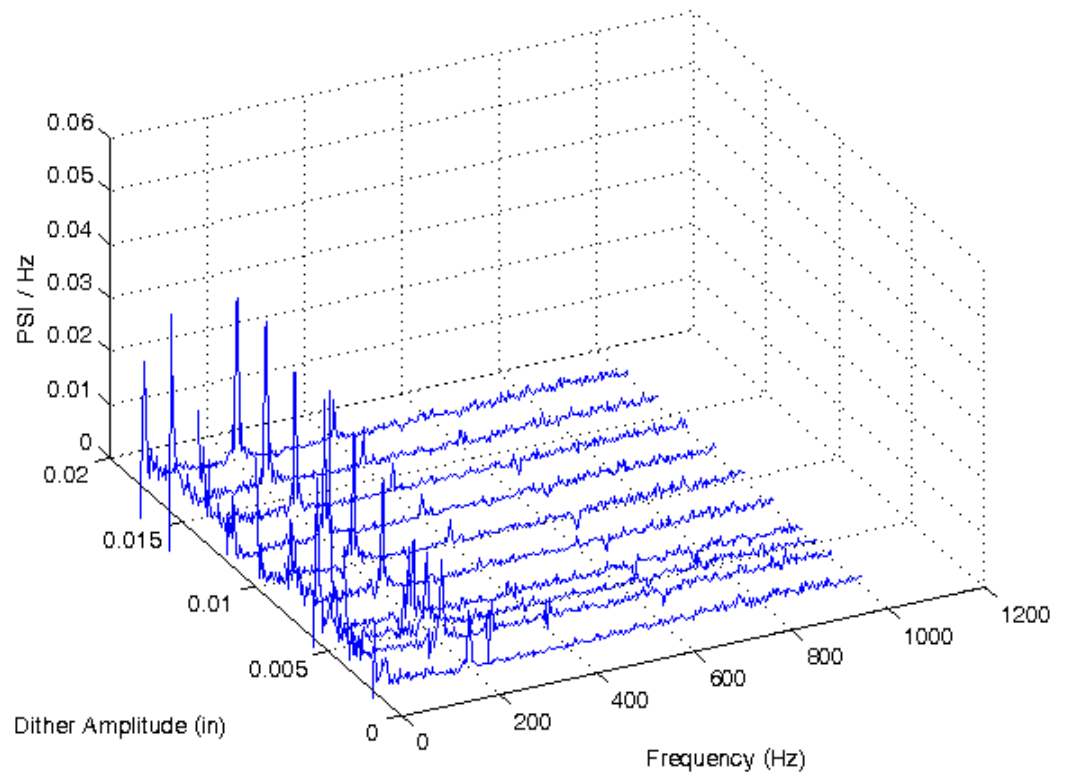

Figure 14: Combustor pressure spectra for varying amplitudes at $200 \mathrm{~Hz}$.
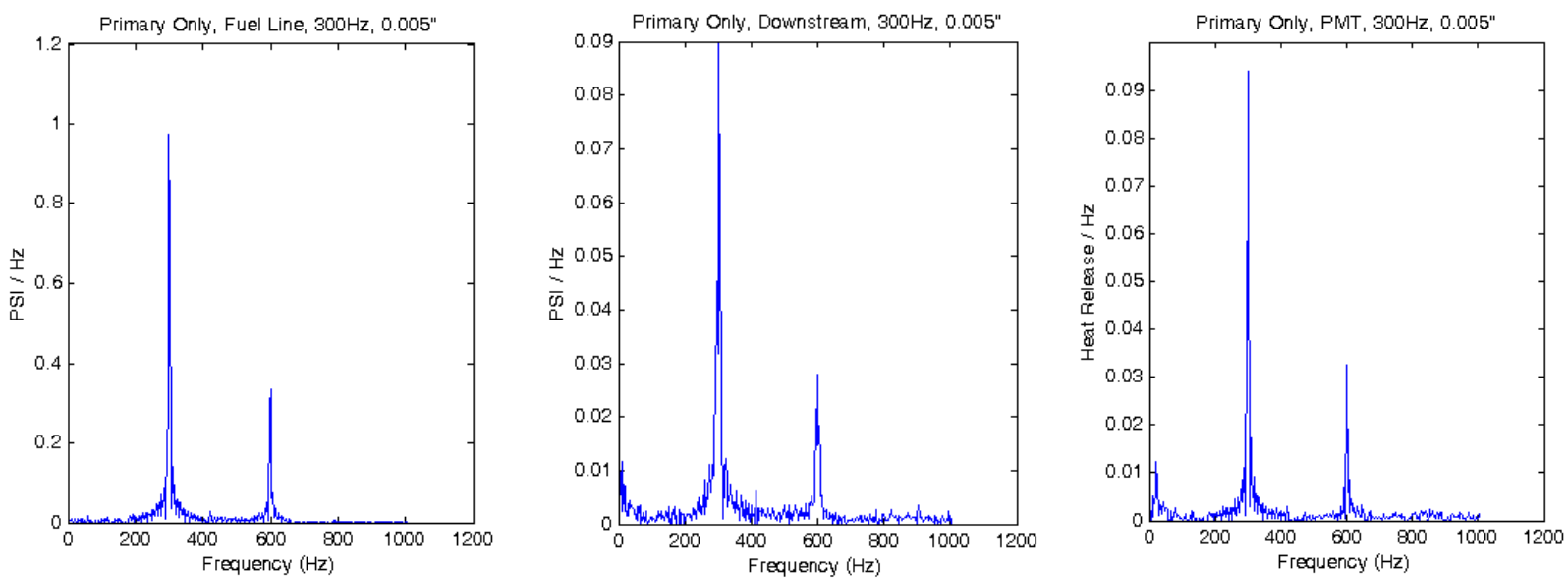

Figure 15: Spectra for $300 \mathrm{~Hz}$ valve excitation; fuel line pressure (left), combustor pressure (center), and heat release (right).

Additional quantitative analysis was performed to investigate the magnitude of the fluctuations in combustor pressure and heat release induced by the valve across the range of frequencies and amplitudes tested. As stated above, for a given valve frequency, the amplitude of the induced oscillations increases linearly with valve amplitude. However, the slope of this increase is not the same for all excitation frequencies. This is evident in the graph shown in Figure 16 for a representative subset of the data 
including 200 and $300 \mathrm{~Hz}$ results. In this case, the vertical axis is the ratio of the heat release variation amplitude (defined as Q') to the mean, i.e., time-averaged, heat release (Qbar). The horizontal axis is valve displacement. The heat release gain at a given frequency is then defined as the slope of the leastsquares line fit to this graph. Note that the gain is higher at $300 \mathrm{~Hz}$ than it is at $200 \mathrm{~Hz}$.

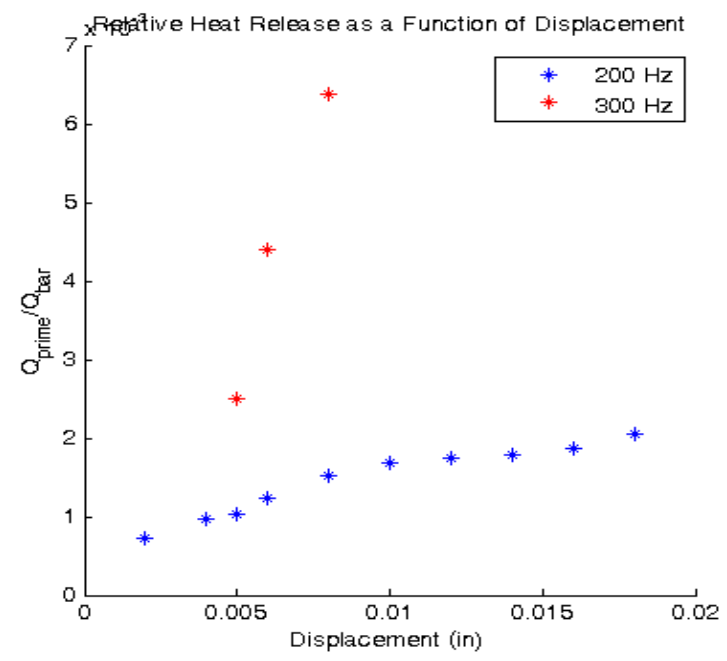

Figure 16: Plot of relative heat release variation vs. valve displacement at 200 and $300 \mathrm{~Hz}$.

Combustor pressure gain was calculated in a similar manner, except that it was normalized to atmospheric pressure. Figure 17 shows plots of combustor pressure gain (left) and heat release gain (right) as a function of valve frequency. Note that both gains trend upward with modulation frequency, indicating that the valve is capable of inducing relatively large changes in combustor response even at very small dither amplitudes.
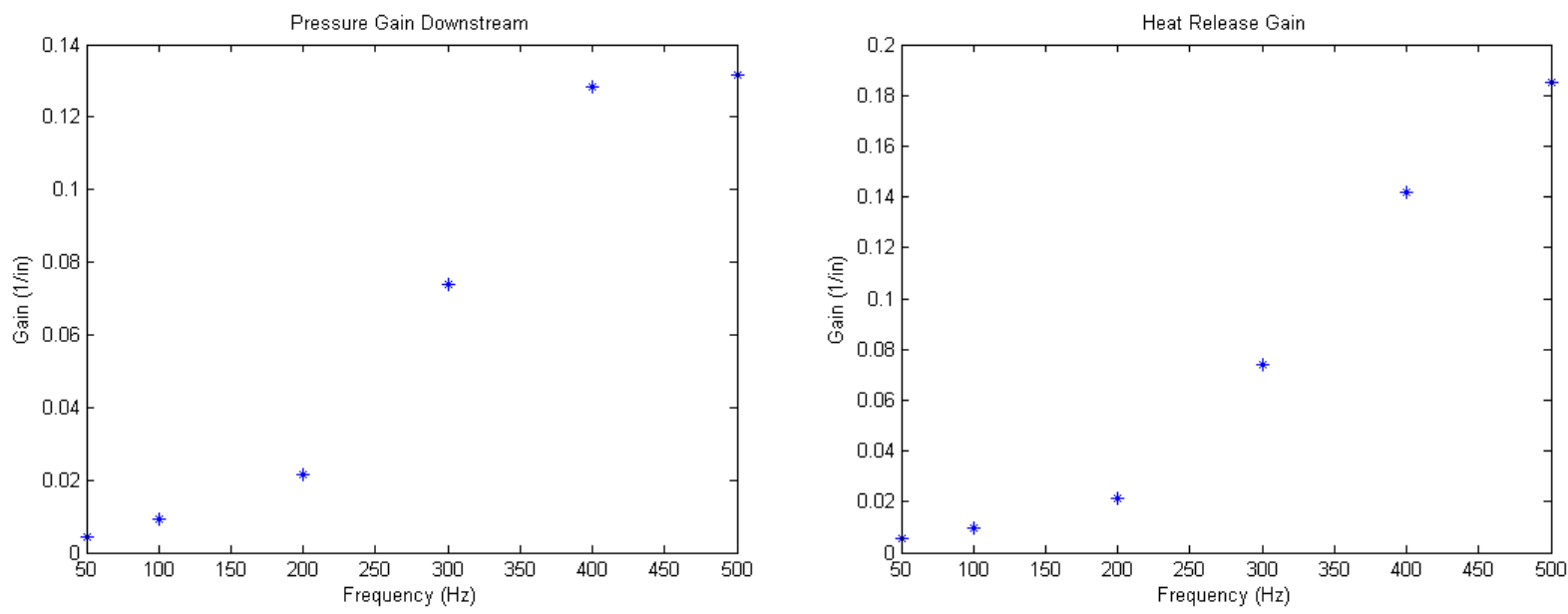

Figure 17: Plots of combustor pressure gain (left) and heat release gain (right) vs. valve frequency. 
High-bandwidth Modulation of H2/Syngas Fuel to Control

Combustion Dynamics in Micro-Mixing Lean Premix Systems

Final Technical Report

\section{SUMMARY}

Under this program, Parker has demonstrated a micro-mixing lean premix hydrogen/syngas injector with improved lean operability over the predecessor design. This was accomplished through fuel staging and sheltering of the primary fuel circuit. In addition, Parker has demonstrated a fuel modulation valve technology that is capable of both proportional and high-bandwidth $(500 \mathrm{~Hz})$ operation, which can be used in future adaptive combustion control systems. The valve was shown to be capable of effecting changes to flame dynamics, heat release, and acoustic signature of an atmospheric combustor through a series of experiments performed at Georgia Tech.

A completed project milestone plan is shown in Table 6 below.

Table 6: Project Milestone Plan

\begin{tabular}{|c|c|c|c|c|}
\hline $\begin{array}{l}\text { Milestone } \\
\text { Description }\end{array}$ & $\begin{array}{l}\text { Original Planned } \\
\text { Completion Date }\end{array}$ & $\begin{array}{l}\text { Revised Planned } \\
\text { Completion Date }\end{array}$ & $\begin{array}{c}\text { Actual } \\
\text { Completion } \\
\text { Date }\end{array}$ & $\begin{array}{l}\text { Verification } \\
\text { Method }\end{array}$ \\
\hline $\begin{array}{l}\text { Execute contract } \\
\text { and subcontract } \\
\text { agreements }\end{array}$ & $10 / 1 / 2010$ & & $1 / 27 / 2011$ & Signed agreements \\
\hline Kickoff Meeting & $10 / 15 / 2010$ & & $12 / 3 / 2010$ & Presentation file \\
\hline Deliver Injectors & $3 / 31 / 2011$ & $8 / 27 / 2011$ & 9/7/2011 & $\begin{array}{l}\text { Hardware shipped } \\
\text { to Georgia Tech }\end{array}$ \\
\hline Deliver Valve & $6 / 30 / 2011$ & $8 / 27 / 2011$ & $10 / 13 / 2011$ & $\begin{array}{c}\text { Hardware shipped } \\
\text { to Georgia Tech }\end{array}$ \\
\hline $\begin{array}{c}\text { Complete } \\
\text { Atmospheric } \\
\text { Combustion } \\
\text { Testing }\end{array}$ & 9/30/2011 & $11 / 30 / 2011$ & $12 / 8 / 2011$ & Data files \\
\hline $\begin{array}{l}\text { Quarterly } \\
\text { Progress } \\
\text { Report(s) }\end{array}$ & $\begin{array}{l}\text { 1/31/2011, } \\
\text { 4/30/2011, } \\
7 / 31 / 2011\end{array}$ & $\begin{array}{l}\text { 1/31/2011, } \\
\text { 4/30/2011, } \\
\text { 7/31/2011, } \\
10 / 31 / 2011 \\
12 / 31 / 2011\end{array}$ & $\begin{array}{c}\text { 2/16/2011, } \\
\text { 4/4/2011, } \\
\text { 7/26/2011, } \\
\text { 10/18/2011, } \\
\text { 2/7/2012 }\end{array}$ & Report file(s) \\
\hline $\begin{array}{c}\text { Final Technical } \\
\text { Report }\end{array}$ & $10 / 31 / 2011$ & $1 / 31 / 2012$ & $2 / 15 / 2012$ & Report file \\
\hline
\end{tabular}


High-bandwidth Modulation of H2/Syngas Fuel to Control

Combustion Dynamics in Micro-Mixing Lean Premix Systems

Final Technical Report

\section{REFERENCES}

[1] Dowling, A. P. and Morgans, A. S., "Feedback Control of Combustion Oscillations," Annual Review of Fluid Mechanics, vol. 37, pp. 151-182, January 2005.

[2] Bloxsidge, G. J., Dowling, A. P., Hooper, N., and Langhorne, P. J., "Active Control of Reheat Buzz," AIAA journal, vol. 26, pp. 783-790, July 1988.

[3] Hoffmann, S., Weber, G., Judith, H., Hermann, J., and Orthmann, A., "Application of Active Control to Siemens Heavy Duty Gas Turbine," in Symposium of the AVT Panel on "Gas Turbine Engine Combustion, Emissions, and Alternative Fuels, "Lisbon, Portugal, 1998, pp. 40-1 to 40-13.

[4] Cohen, J. M. and Banaszuk, A., "Factors Affecting the Control of Unstable Combustors," in Combustion Instabilities in Gas Turbine Engines: Operational Experience, Fundamental Mechanisms and Modeling. vol. 210, T. Lieuwen and V. Yang, Eds. Reston: AIAA, 2005, pp. 581610.

[5] Kopasakis, G. and DeLaat, J. C., "Adaptive Instability Suppression Controls in a Liquid Fueled Combustor," in 38th Joint Propulsion Conference Indianapolis, Indiana: AIAA, 2002.

[6] Johnson, C. E., Neumier, Y., Cohen, J. M., Lee, J. Y., Lubarsky, E., and Zinn, B. T., "Effects of Time Delay and System Noise Upon Active Control of Unstable Combustors," in 39th Aerospace Science Meeting and Exhibit Reno, Nevada: AIAA, 2001.

[7] Kopasakis, G., "High Frequency Adaptive Instability Suppression Controls in a Liquid-Fueled Combustor," in 39th Joint Propulsion Conference and Exhibit Huntsville, Alabama: AIAA, 2003. 